Carlo Nasso

Serena Bertagna

Francesco Mauro

Alberto Marinò

Vittorio Bucci

http://dx.doi.org/10.21278/brod70303

ISSN 0007-215X

eISSN 1845-5859

\title{
SIMPLIFIED AND ADVANCED APPROACHES FOR EVACUATION ANALYSIS OF PASSENGER SHIPS IN THE EARLY STAGE OF DESIGN
}

\author{
UDC 629.541.4:629.5.067 \\ Professional paper
}

\begin{abstract}
Summary
In order to improve the survival capability of passenger and ro-ro ships in event of fire or flooding, in the last few years a set of international Regulations has been issued. In particular, the Regulation SOLAS "Safe Return to Port" is addressed towards design criteria able to guarantee adequate functionality of the ship when a casualty occurs. The Regulation requires the evacuation of the ship when a given threshold of damage (i.e., fire and flood) is exceeded. The evacuation analysis has become of primary importance even in the early-stage design. Indeed, the new amendments to SOLAS Regulation II-2/13.3.2.7 makes the evacuation analysis mandatory for both new and existing passenger and ro-ro ships since the early steps of the project. In this paper, the current IMO Guidelines have been analysed, and a case study for the evacuation of a 3600-person cruise ship has been carried out by means of both a simplified and an advanced method. To perform advanced calculations, two different software, based on virtual reality, have been used and the results have been compared with simplified method ones.
\end{abstract}

Keywords: $\quad$ Evacuation analysis; Ship Safety; Safe Return to Port; Passenger ship

\section{Introduction}

In the last few years, evacuation analysis of passenger ships has become one of the most important theme in shipbuilding. The International Maritime Organization (IMO) has decided to regulate this issue via the International Convention for the Safety of Life at Sea (SOLAS). From 1999 to 2007 the IMO Maritime Safety Committee (MSC) issued three Circulars [1, 2 and 3] about the evacuation analysis and the procedures for calculating the evacuation times for a passenger ship. Based on these Circulars, several studies have been carried out $[4,5$ and 6]. Other studies, instead, have been oriented to evacuation time calculations by means of IMO certified software [7, 8, 9, 10, 11, 12, 13, 14 and 15]. Starting from data ensuing from a 
number of evacuation simulations [16 and 17], in June 2016 IMO issued a new Circular [18] in order to determine the evacuation time and, in case, the presence of congestion points.

Since this could have a huge impact on both the General Arrangements (GA) and the escape routes of the ship, it is mandatory to perform the evacuation analysis immediately after a first GA is at disposal. That means calculations should be performed in the first stages of preliminary design of a vessel.

In this paper, a comparison between the methods to calculate the evacuation time in accordance with the last IMO Circular [18] is presented, along with a test case previously performed by the authors [13 and 19]. The evacuation analysis has been carried out through both simplified and advanced method. In particular, for the advanced method, the two certificated software EVI and AENEAS have been used. In order to properly compare the two methods, a simple scenario that provides a common passenger distribution has been chosen, i.e., the Case 1 (primary evacuation case, night) defined by both the cited Circulars.

\section{Overview of the Regulation framework}

\subsection{Superseded Regulations}

In the last few years, IMO issued some Regulations regarding the evacuation analysis:

- May, 1999 - MSC/Circ.909 "Interim guidelines for a simplified evacuation analysis on ro-ro passenger ships" [1]. With this Circular the evacuation analysis became mandatory for ro-ro ships only. To calculate the evacuation time, a unique method (called "simplified method") based on a hydraulic or flow model was required.

- June, 2001 - MSC/Circ.1001 "Interim guidelines for a simplified evacuation analysis of high-speed passenger crafts". With this Circular the simplified evacuation analysis was expanded also to high-speed passenger crafts.

- June, 2002 - MSC.1/Circ.1033 - "Interim guidelines for a simplified evacuation analysis for new and existing passenger ships" [2]. For the first time the evacuation analysis was applied to all passenger ships. To calculate the evacuation time, two distinct methods were allowed: the "simplified method", which was already present in the previous Circulars, and a so-called "advanced method" based on experimental data. The first applications of the advanced method were criticized due to the lack of significant experimental data. In fact, there were little or no data relating to passenger response times in maritime environment, so that data used in the guidelines were derived from land-based building measurements.

- October, 2007 - MSC.1/Circ.1238 "Guidelines for evacuation analysis for new and existing passenger ships" [3]. To overcome the limits of the previous Regulation, the findings of a particular project (called Fire Exit) funded by the European Union were adopted in this Circular. In such a project, sea trials concerning the response times during the evacuation of a Grimaldi ro-ro ferry sailing between Civitavecchia and Barcelona in April 2005 were performed. The sea trials clearly demonstrated that the response times calculated by the MSC/Circ.1033 were not sufficiently accurate. Therefore, the Fire Exit sea trial data were submitted to IMO and incorporated within the new analysis protocol reported in the MSC/Circ.1238. Also in such a Circular both a simplified and an advanced method was proposed.

- June, 2015 - MSC/Circ.1166 "Guidelines for a simplified evacuation analysis for high-speed passenger crafts". This Circular superseded the previous interim MSC/Circ.1001. 


\subsection{Regulation in force}

On June 6, 2016 - MSC.1/Circ. 1533 "Revised guidelines on the evacuation analysis for new and existing passenger ships" has been issued and all the previous Regulations on the matter were superseded. Through this Circular, evacuation analysis is made mandatory not only for ro-ro passenger ships, but also for other passenger ships built on or after January 1 , 2020. The Regulation makes mandatory the determination of the evacuation time and encourages to perform such an analysis also on existing passenger ships. In this manner it is possible to identify, in case, the presence of congestion points or critical areas where to adopt proper operational measures in order to not exceed the maximum allowable evacuation time. As the previous Regulations, also this one allows to evaluate the evacuation time by either the simplified or the advanced method. The simplified method is based on a "fluid-dynamic similarity", in which corridors and stairs are the tubes, while the passengers are the fluid that runs through them; for the analysis it is necessary to follow a specific procedure as indicated in the Circular. In the advanced method, instead, passengers are represented as individuals with particular features, and the calculation of the evacuation time is carried out by a software based on virtual reality. In both methods, the main objective is the evaluation of the total evacuation duration, as well as the identification of congestion points and areas where intense counter or cross flows are present.

The main innovations introduced by the MSC.1/Circ.1533 are:

- explicit recommendations to perform the evacuation analysis already during the early-stage design;

- the harmonization of the evacuation time calculation carried out by the simplified or the advanced method;

- documentation of the crossing, counter or dividing flow areas, in order to allow the crew to take adequate measures in tackling these critical areas;

- the introduction of a voluntary additional day case that foresees the crowding in large open deck spaces;

- the introduction of a voluntary additional case concerning the embarkation in order to prove that such an operation can be achieved within 30 minutes.

\section{Simplified method}

By the simplified method, the total evacuation duration is calculated and compared with an allowable time $n$, which depends on the vessel type (ro-ro or other passenger ship), and the number of Main Vertical Zones (MVZs). This represents the time necessary for all the persons on board (passengers and crew) to reach the pertinent assembly stations, embark on the survival crafts and launch them. To tackle the evacuation analysis, the following components must be calculated:

- Response duration $(R)$, which considers for each person the effective reaction time to an emergency situation. This duration begins upon initial notification of the emergency (usually an alarm) and ends when the passenger realizes the situation and starts to move toward the assembly station.

- Total travel duration (T), which includes the time spent to move all the persons on board from the place occupied upon the emergency notification to the assembly stations.

- Embarkation and launching duration $(E+L)$, which represents the time required for the ship abandonment of all the persons present on board. The evaluation of $E+L$ must be done with reference to full-scale trials, simulations or data provided by the manufacturers of the evacuation systems. In any case $E+L$ must not exceed $30 \mathrm{~min}$. 
About the initial distribution of people on board, the MSC.1/Circ.1533 is based on the Ch.13 of the International Code for Fire Safety Systems (FSS Code), distinguishing between "night scenario" and "day scenario" as follows:

- "night scenario" - passengers in cabins with maximum berthing capacity fully occupied; $2 / 3$ of crew members in their cabins and the remaining $1 / 3$ so distributed:

$50 \%$ located in the service spaces;

$25 \%$ located at their emergency stations;

$25 \%$ initially located at the assembly stations; successively they should proceed towards the most distant passenger cabin assigned to that assembly station, in counter flow with the evacuees. Once this passenger cabin is reached, these crew members are no longer considered in the simulation.

- "day scenario" - passengers in public space occupy 3/4 of the maximum capacity; $1 / 3$ of the crew members in their accommodation spaces (cabins and crew day spaces); $1 / 3$ of the crew members in the public spaces and the remaining $1 / 3$ distributed as follows:

$50 \%$ located in the service spaces;

$25 \%$ located at their emergency duty locations;

$25 \%$ initially located at the assembly stations; successively, they should proceed towards the most distant passenger cabin assigned to that assembly station, in counter flow with the evacuees. Once this passenger cabin is reached, these crew members are no longer considered in the simulation.

The Circular imposes to consider in the evacuation analysis at least four scenarios (Cases 1 to 4), which are characterized by different distributions and features of persons (both passengers and crew):

- Case 1 (primary evacuation case, night) - persons distributed as in "night scenario"; the entire ship is considered; evacuation is carried out along the main means of escape.

- Case 2 (primary evacuation case, day) - persons distributed as in "day scenario"; evacuation scenario as per Case 1 .

- Case 3 (secondary evacuation case, night) - persons distributed as in "night scenario"; only the MVZ generating the longest assembly duration is further investigated according with one of the following alternatives (but Alternative 1 is recommended):

Alternative 1: a main escape route previously used in the considered MVZ is unavailable for the simulation;

Alternative 2: $50 \%$ of persons of the most populated adjacent MVZ is forced to move into the considered MVZ.

- Case 4 (secondary evacuation case, day) - persons distributed as in "day scenario"; evacuation scenario as per Case 3 .

One of the innovations of the Circular consists in the introduction of two new optional scenarios, which may be considered if appropriate:

- Case 5 (open deck, day) - if there is an open deck outfitted for use by passengers, having a gross surface area larger than $400 \mathrm{~m}^{2}$ or with more than 200 persons accommodated, the open deck is considered as an additional public space with an initial density of 0.5 person $/ \mathrm{m}^{2}$, and so a new person distribution for Case 2 must be simulated.

- Case 6 (embarkation) - if embarkation and assembly stations are not coincident, the travel duration from assembly station to the entry point of the survival crafts should be considered in the $E+L$ evaluation. All persons, which the ship is certified to 
carry, are distributed in the assembly stations according to their capacity. Possible congestions directly in front of the entry point of the survival crafts should be considered in the simulation.

An innovation introduced by the MSC.1/Circ.1533 is the harmonization of the total evacuation duration (tтот) for both the simplified and the advanced method (Fig.1). Indeed, the performance standard to be verified for the two methods is the same:

$$
t_{\text {TOT }}=1.25(R+T)+\frac{2}{3}(E+L) \leq n
$$

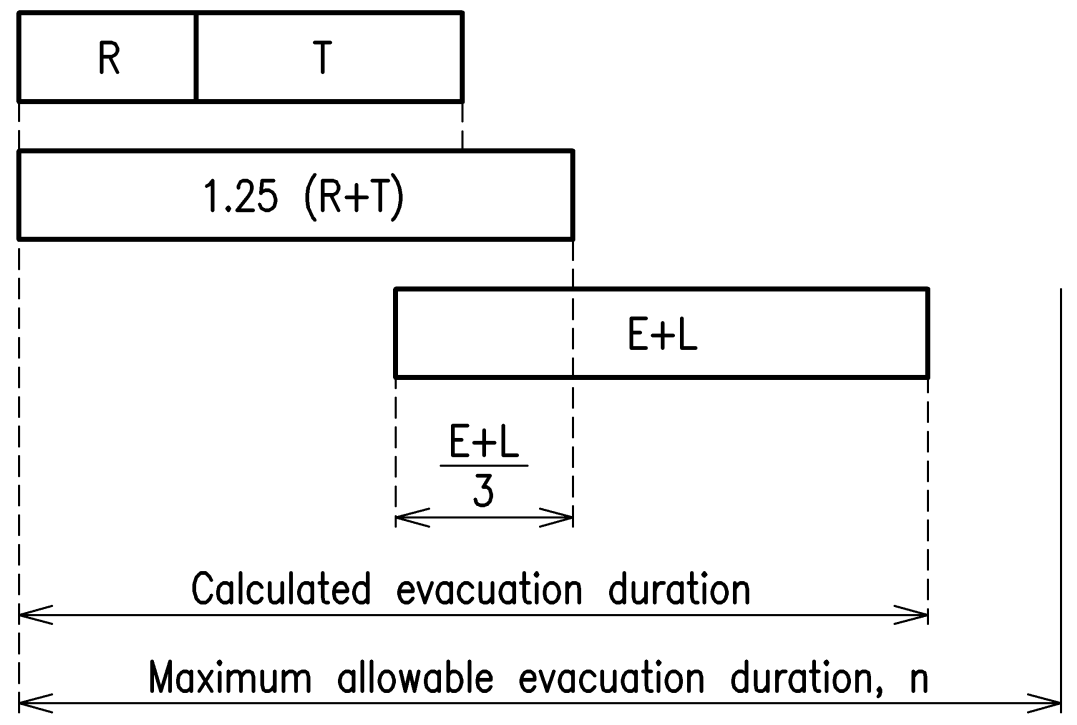

Fig. 1 Representation of performance standard for simplified and advanced method.

The reference duration $n$ must be equal to 60 minutes both for ro-ro vessels and for other passenger ships with less than three MVZs, and to 80 minutes for passenger ships with more than three MVZs.

About the response duration, the Circular imposes to consider $R$ equal to 10 minutes for the night time scenarios (Cases 1 and 3) and to 5 minutes for day time scenarios (Cases 2, 4 and 5).

In the simplified method, the travel duration $T$ is calculated as a function of the passenger and crew flow. In the Circular, a procedure to establish the travel duration $T$ is described, as a function of the highest travel duration in ideal condition denoted by $t_{l}$. For each Case analysed, with reference to a deck, $t_{I}$ is evaluated through the following sum:

$$
t_{I}=t_{F}+t_{\text {deck }}+t_{\text {stair }}+t_{\text {assembly }}
$$

where:

- $t_{F}$ represents the flow duration. It depends on the specific flow of persons $\left(F_{S}\right)$, which is the number of persons passing a point of the escape route per unit time and unit clear width. The specific flow $F_{S}$ is given from tables of the Circular as a function of both the type of facility (corridors, stairs down or up, doorways) and the initial density of persons $(D)$. It is so possible to predict the number of persons passing a particular point of an escape route per unit time, and determine the calculated flow of person $\left(F_{C}\right)$ :

$$
F_{C}=F_{S} W_{C}
$$


in which $W_{C}$ is the clear width of the different means of escape. The flow duration is the total time needed for $N$ persons (passengers and crew) to move past a point in the egress system and it is given by the following formula:

$$
t_{F}=\frac{N}{F_{C}}
$$

- $t_{\text {deck }}$ is the deck travel duration. It represents the time necessary to move from the farthest point of the escape route of a deck to the stairway.

- $t_{\text {stair }}$ is the stairway travel duration. It is the time required to travel the stairway.

- $t_{\text {assembly }}$ is the assembly travel duration. It represents the time necessary to move from the end of the stairway to the entrance of the assigned assembly station.

In order to exceed the limits of the hydraulic similarity, two corrective factors $(\gamma$ and $\delta$ ) are introduced, so that the travel duration $T$ of a specific Case is given by:

$$
T=(\gamma+\delta) t_{I}
$$

where $\gamma$ must be taken equal to 2 for Case 1 and 2, and to 1.3 for Case 3 and 4, while $\delta$ (the counter-flow correction factor) must be taken equal to 0.3 for all Cases.

The performance standards should be carried out through the formula (1) for all the Cases analysed. After verifying that the allowable duration $n$ imposed by the Circular is respected, also possible congestion points should be identified. These points are:

- the spaces where the initial density is higher than 3.5 person $/ \mathrm{m}^{2}$;

- the locations where the difference between the inlet and outlet calculated flow $\left(F_{C}\right)$ is more than 1.5 person per second.

Aim of the evacuation analysis is to identify and eliminate, as far as practicable, the congestion points because anyway they represent a potential danger during the evacuation and abandonment of the ship. The identification of these points is quite difficult through the simplified method. Therefore, also for this reason, the IMO Maritime Safety Committee introduced the advanced method since the MSC.1/Circ.1238 issued on October, 2007.

\section{Advanced method}

In the advanced method the hydraulic similarity of the simplified method is exceeded since all persons on board are represented as individuals with particular abilities and response durations; moreover, the relationship between passengers, crew and layout of the ship is considered.

In this method, the evacuation analysis is performed with a specific software based on virtual reality, which uses different pedestrian algorithms for simulating the behaviour of evacuees. Through a randomized approach, the travel duration $T$ is calculated: for each Case analysed a minimum of 500 different simulations should be done, but this number may be reduced to 50 if an appropriate convergence criterion is complied with. The simulations are made up considering 100 different randomly-generated populations, and for each population a set of parameters influencing the evacuation and collected in 4 different categories are fixed:

- category geometrical, which considers the layout of the escape route;

- category population, which considers a range of parameters concerning persons and population demography;

- category environmental, which considers the static and dynamic conditions of the ship (even if presently the figures of such parameters are not reliable due to the lack of experimental data). For this reason, in the last few years several experiments on 
human behaviour in case of storm have been performed using particular platforms which simulate the ship motions [21, 22 and 23];

- category procedural, which considers the assistance of the crew in emergency situations.

Through this procedure, all scenarios are investigated and for each one a value of total assembly duration $t_{A}$ (defined as the maximum individual assembly duration) is determined. The travel duration $t_{I}$ to be associated at each Case corresponds at the 95-percentile of $t_{A}$ obtained from the various simulations. The total travel duration $T$ to be considered in the performance standard (1) is the maximum value of the travel durations $t_{I}$ drawn from the analyses of all Cases examined.

The virtual reality simulators use different pedestrian algorithms, which are based on peculiar mathematical models (statistical models, queuing models, route-choice models, gaskinetic models, etc.). The main certified software are:

- EVI, developed by the University of Strathclyde-Glasgow;

- ANEAS, developed in collaboration between DNV-GL and TraffGo;

- EXODUS, developed by the University of Greenwich;

- ODIGO, developed by the French engineering company Principia;

- VELOS, developed by the National Technical University of Athens.

In this paper, AENEAS and EVI software are used to carry out the calculations required by the advanced method to determine the total travel duration $T$.

\subsection{AENEAS}

AENEAS, developed by DNV-GL and TraffGo, is a multi-agent software in which passengers and crew (generically, the so-called agents) are represented with particular attitudes, abilities and goals. The software is based on a square-cell discretization of the various decks (Fig. 2) with the cell side $0.4 \mathrm{~m}$ long. Each agent can occupy only one cell at each time step, and he moves from cell to cell.

The software is composed by three modules:

- AENEASed (editor), which allows to import a CAD file and to convert it into a relevant cellular grid. After the discretization it is possible to modify the decks geometries. Furthermore, it is necessary to define the escape routes and distribute the agents in the ship distinguishing between passengers and crew.

- AENEASsim (simulator), which allows to load the project created in the editor and to run the simulation. The demographic parameters of passengers and crew may be fixed either by default (according to the indication present in the MSC.1/Circ.1533) or properly established by the user (in accordance with the actual population present on board). The results of each Case are synthesized by the probability density function of the travel evacuation duration associated to each simulation and by the relevant significant evacuation time (assumed as the 95-percentile). Moreover, sketches of all the congestion points of the simulation having a travel evacuation duration equal to the determined significant evacuation time are given.

- AENEASview (viewer), which allows to view the evacuation process in a threedimensional environment. Through this video, the user can easily identify the congestion points in the escape routes during the evacuation phases.

In order to represent the decks in a realistic manner, the following types of cell can be used (Fig. 2 and 3):

- Free cells (white coloured), which can be occupied by the agents during the evacuation; 
Nasso Carlo, Bertagna Serena,

Mauro Francesco, Marinò Alberto, Bucci Vittorio
Simplified and advanced approaches for evacuation analysis of passenger ships in the early stage of design

- Wall cells (black coloured) for the obstacles (as walls, furniture, etc.) along the escape routes. These cells cannot be occupied by the agents;

- Goal cells (identified by a tag given by the user) for the objective (as an assembly station or a cabin) to be achieved by each agent;

- Door cells (red coloured) for the doors, where a reduction of the walking speed of the agents occurs;

- Step cells (cyan coloured) for stairways (both up- and down-stairs).

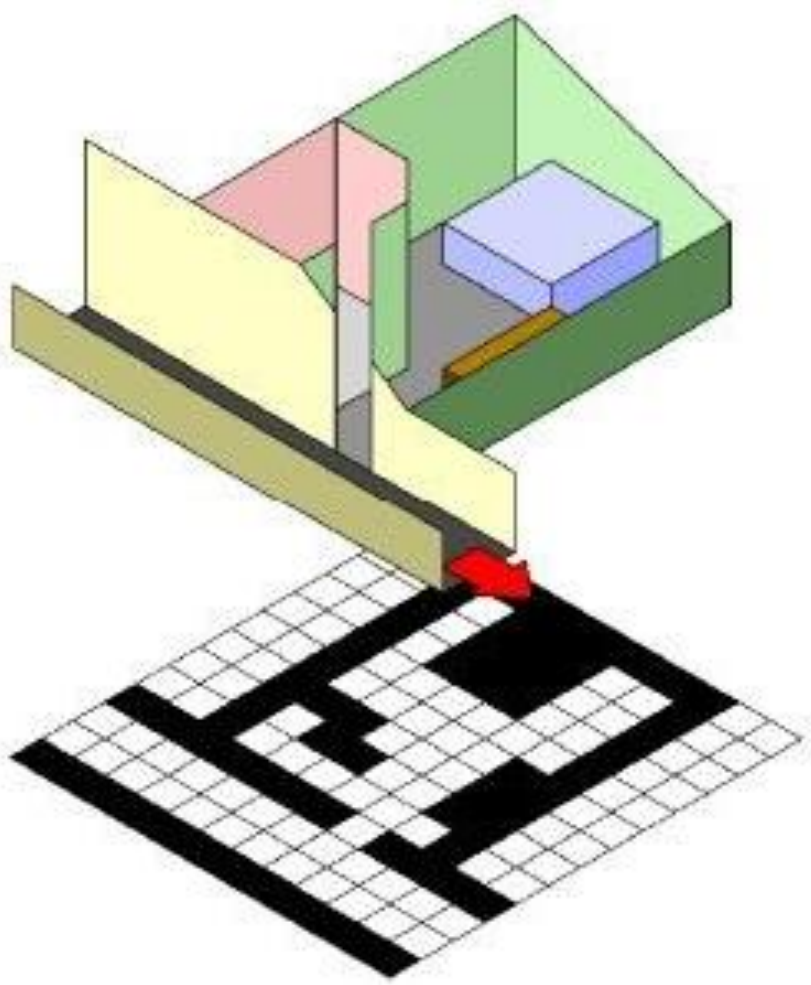

Fig. 2 Discretization of a cabin in AENEAS

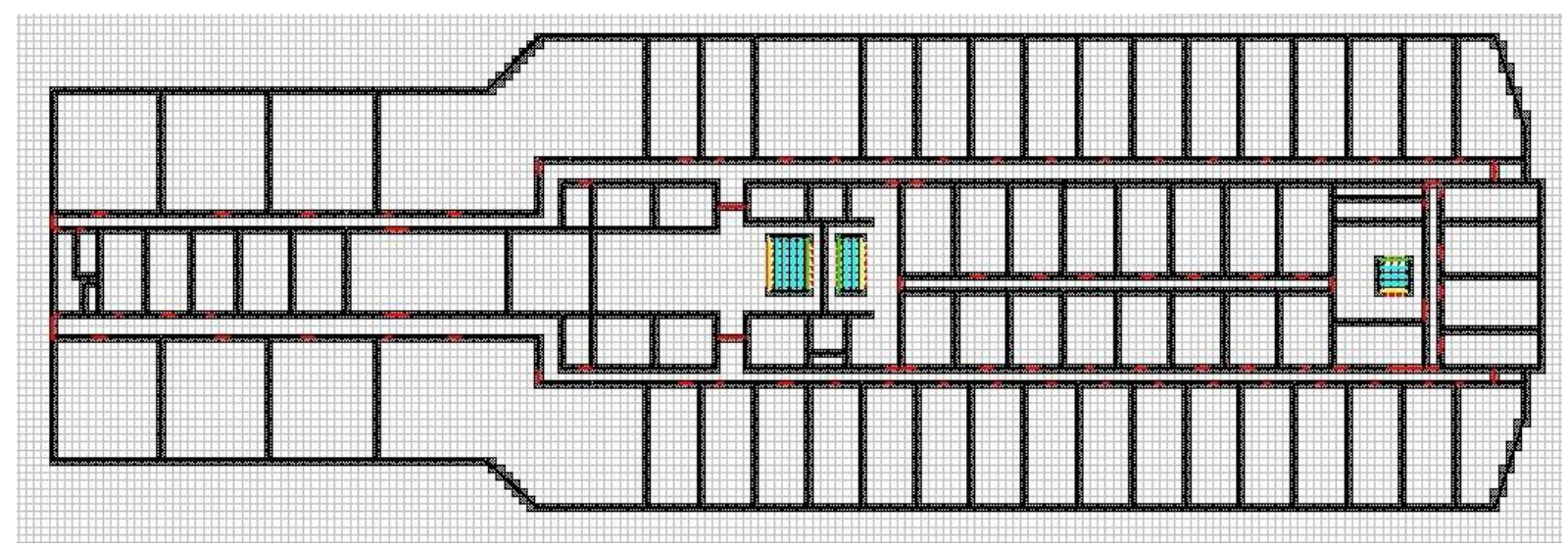

Fig. 3 Square-cell discretization of a deck in AENEAS

During the simulation, each agent jumps from cell to cell, using the neighbouring free, door or step cell in order to reach its assigned goal cell. Each agent runs along an escape route, which may be specified either by the user or by default as the way towards the closest 
goal cell. For the orientation, agents make use of a "potential value" associated to each cell: for a given route, the cells have a value that increases proportionally to the distance from the goal cells. The agent finds its way by comparing the potential value of the cell occupied with the value of the adjacent cells. During the evacuation, the generic agent can choose between 8 cells neighbouring (Fig. 4).

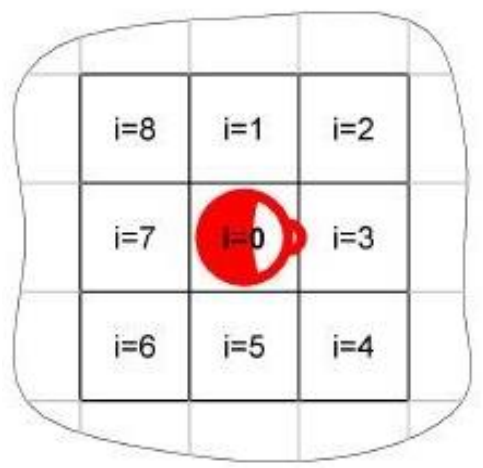

Fig. 4 Cell scheme for orientation

Standing on a certain cell $i=0$ (central cell), the occupation of an adjacent cell $i$ is done on the basis of the greatest probability $p_{i}$ :

$$
p_{i}=e^{-\frac{\left(P_{i}-P_{0}\right)+S}{S}}
$$

being $P_{0}$ the value of the potential of the central cell $(i=0)$ and $P_{i}$ that of a generic adjacent cell $i$. Indeed, $S$ is the value of the $S$ way that represents the accuracy with which an agent follows the course of the potential.

\subsection{EVI}

EVI, developed by the Ship Stability Research Centre of the University of StrathclydeGlasgow and distributed by Safety at Sea, is another multi-agent software. It bases on the concept of "evacuability" (indeed, EVI is the acronym of EVacuation Index) to be intended as the ability of a person to evacuate the ship. This index takes into account a wide range of parameters, which can be collected in two separate groups, namely the Initial Conditions and the Evacuation Dynamics. The first group considers the layout of the ship (env), the demography of the population and its initial distribution $(d)$ and the response time to danger $(r)$, while the second group takes into account the walking speed of each agent, the interaction between passengers and crew and between agent and layout of the ship.

The ship environment is set up starting from the 2D general arrangement drawings of decks in order to create a 3D model of the spaces involved in the evacuation (Fig.5 and Fig.6). 


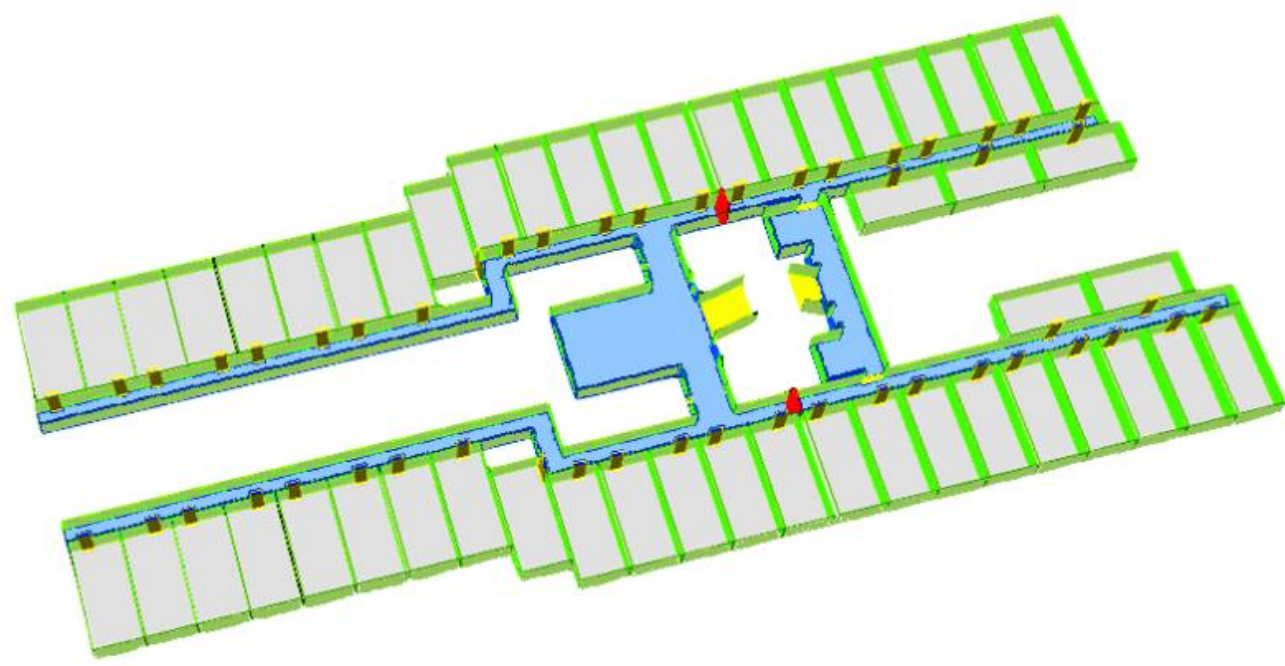

Fig. 5 General deck in EVI

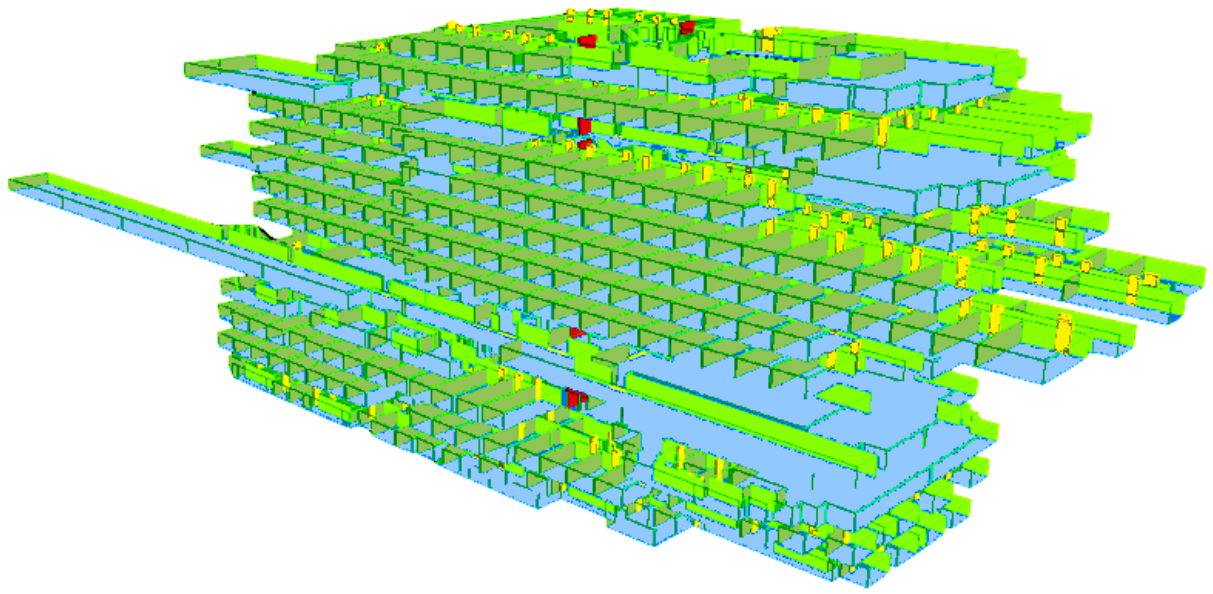

\section{Case Study}

Fig. 6 3D model in EVI

An existing cruise ship (Fig. 7) has been considered to carry out the evacuation analysis in accordance with the MSC.1/Circ.1533.

In particular, both the simplified and the advanced method have been performed with reference to the MVZs 5 and 6 (Fig. 7), which represent the most critical Main Vertical Zones of the ship due to the presence of public areas.

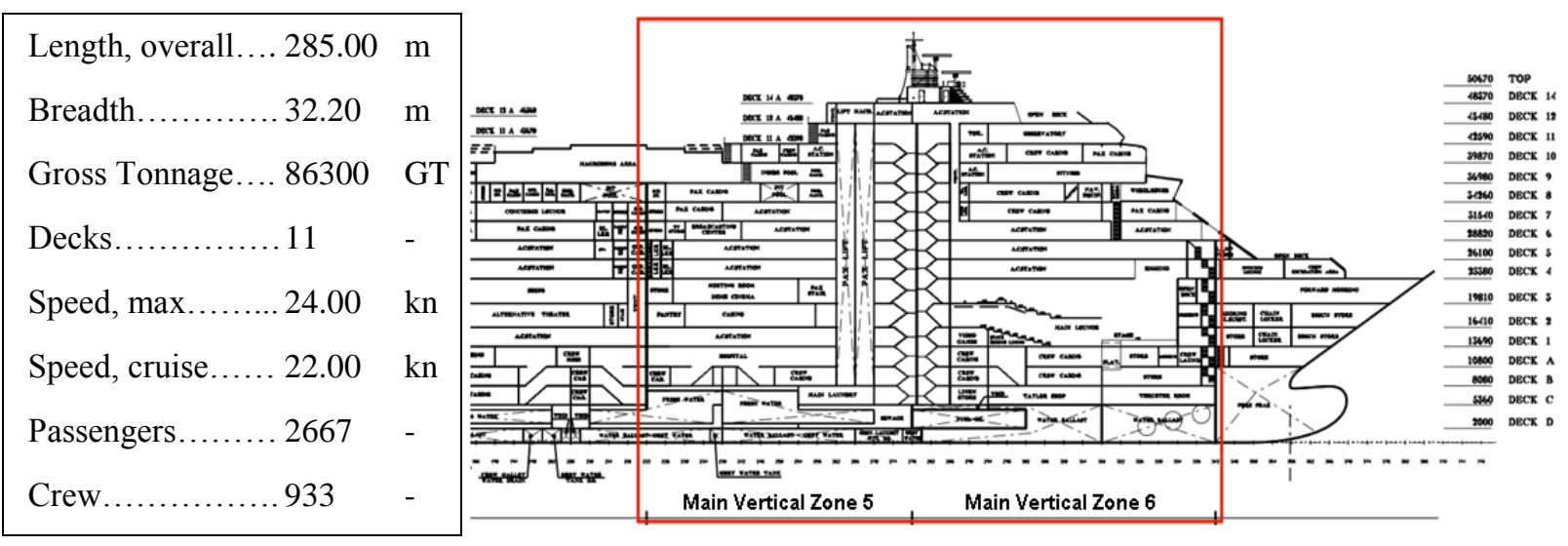

Fig. 7 Ship characteristics and the MVZs considered for the evacuation analysis in the case study 


\subsection{Simplified method application}

In the simplified method, only the primary cases (i.e., Case 1 and Case 2) have been considered for the performance standard verification. Only the main escape routes have been taken into account to calculate the total evacuation duration. In the first step, this method verifies the layout of the considered MVZs. In particular, the length of the corridors, the width of the doors and of the stairways, and the area of the landings should comply with the requirements of Ch.13 of FSS Code. An example of the topological analysis, with reference to Deck 6, is reported in Table 1 and Figure 8. Successively, in accordance with the MSC.1/Circ.1533 the considered MVZs are populated, and the calculation procedure can start. The population distribution obtained for the case study is shown in Table 2. By means of the formulae reported in the Circular, the stairway travel duration $t_{\text {stair }}$, the deck travel duration $t_{\text {deck }}$ and the flow duration $t_{F}$ have been calculated for each deck, while the assembly travel duration tassembly has been determined only for the deck where the assembly stations are located The results for Case 1 are reported in Table 4 as example of the above described procedure. The sum of these values corresponds to the highest travel duration in ideal condition $t_{I}$ for each deck. The travel duration $T$ to be applied in the performance standard (1) is the maximum $t_{I}$ calculated, corrected by $\gamma$ and $\delta$. The results obtained for Case 1 and 2 are reported in Table 7: in both cases, the performance standard as indicated in the Circular (i.e., 80 minutes) is fully met.
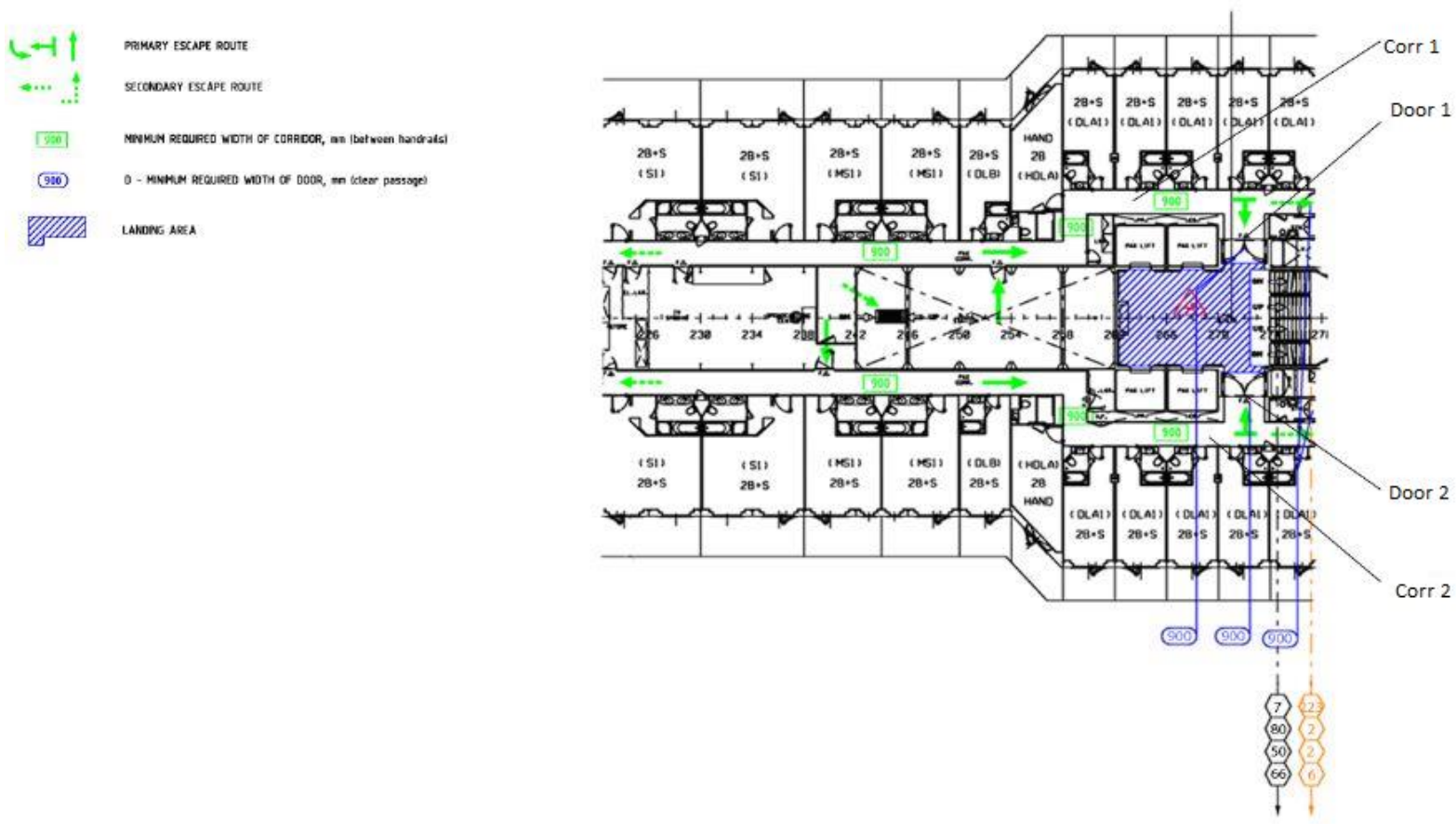

Fig. 8 Layout of Deck 6

Table 1 Layout of Deck 6

\begin{tabular}{|c|c|c|c|}
\hline Deck 6 & Width $\mathrm{W}_{\mathrm{C}}[\mathrm{m}]$ & Length $[\mathrm{m}]$ & Area $\left[\mathrm{m}^{2}\right]$ \\
\hline Corridor 1 & 0.90 & 36.90 & 37.40 \\
\hline Corridor 2 & 0.90 & 36.90 & 37.40 \\
\hline Door 1 & 0.90 & $/$ & $/$ \\
\hline Door 2 & 0.90 & $/$ & $/$ \\
\hline Stairway 7 & 5.20 & 3.63 & $/$ \\
\hline
\end{tabular}


Nasso Carlo, Bertagna Serena,

Mauro Francesco, Marinò Alberto, Bucci Vittorio

Table 2 Population distribution (simplified method)

\begin{tabular}{|c|c|c|c|c|}
\hline & \multicolumn{2}{|c|}{ Night (Case 1) } & \multicolumn{2}{c|}{ Day (Case 2) } \\
\hline Deck & Passengers & Crew & Passengers & Crew \\
\hline C & 0 & 8 & 0 & 12 \\
\hline B & 0 & 43 & 0 & 22 \\
\hline A & 0 & 30 & 0 & 21 \\
\hline 1 & 142 & 2 & 0 & 92 \\
\hline 2 & 0 & 4 & 139 & 14 \\
\hline 3 & $/$ & $/$ & $/$ & $/$ \\
\hline 4 & 60 & 2 & 0 & 2 \\
\hline 5 & 89 & 2 & 0 & 2 \\
\hline 6 & 64 & 2 & 0 & 6 \\
\hline 7 & 48 & 2 & 0 & 2 \\
\hline 8 & 78 & 2 & 0 & 2 \\
\hline 9 & 0 & 7 & 208 & 15 \\
\hline 10 & 47 & 1 & 0 & 3 \\
\hline 11 & 20 & 1 & 0 & 20 \\
\hline TOT & 548 & 106 & 347 & 213 \\
\hline
\end{tabular}

Simplified and advanced approaches for evacuation analysis of passenger ships in the early stage of design

Table 3 Population distribution (advanced method)

\begin{tabular}{|c|c|c|c|c|}
\hline & \multicolumn{2}{|c|}{ Night (Cases 1 and 3) } & \multicolumn{2}{c|}{ Day (Cases 2 and 4) } \\
\hline Deck & Passengers & Crew & Passengers & Crew \\
\hline C & 0 & 8 & 0 & 12 \\
\hline B & 0 & 175 & 0 & 88 \\
\hline A & 0 & 89 & 0 & 51 \\
\hline 1 & 142 & 4 & 202 & 15 \\
\hline 2 & 0 & 11 & 402 & 22 \\
\hline 3 & 0 & 17 & 324 & 23 \\
\hline 4 & 121 & 4 & 0 & 2 \\
\hline 5 & 150 & 4 & 0 & 2 \\
\hline 6 & 173 & 4 & 0 & 6 \\
\hline 7 & 124 & 4 & 0 & 2 \\
\hline 8 & 108 & 4 & 0 & 2 \\
\hline 9 & 0 & 14 & 268 & 28 \\
\hline 10 & 92 & 20 & 0 & 10 \\
\hline 11 & 20 & 7 & 198 & 12 \\
\hline TOT & 930 & 365 & 1394 & 275 \\
\hline
\end{tabular}

Table 4 Results of the different durations obtained from the simplified method (Case 1)

\begin{tabular}{|c|c|c|c|c|c|c|}
\hline Deck & $\mathrm{t}_{\mathrm{F}}[\mathrm{s}]$ & $\mathrm{t}_{\text {deck }}[\mathrm{s}]$ & $\mathrm{t}_{\text {stair }}[\mathrm{s}]$ & $\mathrm{t}_{\text {assembly }}[\mathrm{s}]$ & $\mathrm{t}_{\mathrm{I}}[\mathrm{s}]$ & $\mathrm{T}[\mathrm{s}]$ \\
\hline 11 & 63.5 & 25.3 & 53.2 & 13.1 & 155.1 & 356.8 \\
\hline 10 & 63.5 & 25.3 & 46.4 & 13.1 & 148.3 & 341.1 \\
\hline 9 & 63.5 & 17.7 & 39.8 & 13.1 & 134.1 & 308.4 \\
\hline 8 & 63.5 & 40.2 & 33.0 & 13.1 & 149.8 & 344.6 \\
\hline 7 & 63.5 & 34.9 & 26.4 & 13.1 & 137.9 & 317.1 \\
\hline 6 & 63.5 & 37.5 & 19.8 & 13.1 & 133.9 & 308.0 \\
\hline 5 & 63.5 & 42.8 & 13.2 & 13.1 & 132.6 & 304.9 \\
\hline 4 & 63.5 & 36.8 & 6.60 & 13.1 & 120.0 & 276.1 \\
\hline 3 & 0.00 & 0.00 & 0.00 & 13.1 & 13.10 & 30.20 \\
\hline 2 & 69.6 & 11.7 & 10.6 & 13.1 & 105.0 & 241.5 \\
\hline 1 & 69.6 & 64.8 & 18.9 & 13.1 & 166.4 & 382.7 \\
\hline $\mathrm{A}$ & 69.6 & 31.3 & 26.6 & 13.1 & 140.7 & 323.6 \\
\hline B & $\mathbf{6 9 . 6}$ & $\mathbf{5 8 . 2}$ & $\mathbf{3 3 . 8}$ & $\mathbf{1 3 . 1}$ & $\mathbf{1 7 4 . 7}$ & $\mathbf{4 0 1 . 7}$ \\
\hline $\mathrm{C}$ & 69.6 & 7.20 & 41.0 & 13.1 & 130.9 & 301.0 \\
\hline
\end{tabular}

\subsection{Advanced method application}

The advanced method has been carried out by both AENEAS and EVI tools. In both software, the MVZs considered in the case study have been modelled and populated following the indications of the MSC.1/Circ.1533 (Table 3). In particular, in accordance to Annex 3 of the Circular, the population's composition in terms of age and gender has been determined (Table 5). The two software give a 3D representation of the evacuation phases (Fig. 9 and 10). 
Table 5 Composition of the population in the MVZs 5 and 6

\begin{tabular}{|c|c|c|c|}
\hline Population groups - passenger & $\begin{array}{c}\text { Percentage } \\
{[\%]}\end{array}$ & $\begin{array}{c}\text { Night Cases } \\
\text { [persons] }\end{array}$ & $\begin{array}{c}\text { Day Cases } \\
\text { [persons] }\end{array}$ \\
\hline Females younger than 30 years & 7 & 65 & 98 \\
\hline Females $30-50$ years & 7 & 65 & 98 \\
\hline Females older than 50 years & 16 & 149 & 223 \\
\hline Females older than 50 years, mobility impaired (1) & 10 & 93 & 139 \\
\hline Females older than 50 years, mobility impaired (2) & 10 & 93 & 139 \\
\hline Males younger than 30 years & 7 & 65 & 98 \\
\hline Males 30-50 years & 7 & 65 & 98 \\
\hline Males older than 50 years & 16 & 149 & 223 \\
\hline Males older than 50 years, mobility impaired (1) & 10 & 93 & 139 \\
\hline Males older than 50 years, mobility impaired (2) & 10 & 93 & 139 \\
\hline TOTAL passengers & 100 & 930 & 1394 \\
\hline \multicolumn{4}{|l|}{ Population groups - crew } \\
\hline Crew females & 50 & 182 & 137 \\
\hline Crew males & 50 & 183 & 138 \\
\hline TOTAL crew & 100 & 365 & 275 \\
\hline
\end{tabular}

For each Case, randomly generated simulations have been run. In AENEAS the results of each Case are statistically elaborated in order to obtain the total assembly duration $t_{A}$ probability frequency (Fig. 11, with reference to Case 1), and the 95-percentile value is assumed as the highest travel duration $t_{I}$ for the considered Case (the green bar in Fig. 11). Successively, the same analysis is carried out for the other Cases, and the travel duration $T$ to be adopted for the performance standard verification is assumed as the maximum of the four calculated travel duration $t_{I}$ (Table 8).

In EVI, for each Case, fifty randomly generated simulations have been analysed and the corresponding evacuation durations $t$ evaluated. In Table 6 the evacuation durations $t$ of the simulations for the Case 1 are given along with the corresponding evacuability index. In particular, it is highlighted the evacuability at the 95-percentile of the distribution that defines the highest travel duration $t_{I}$ of the considered Case.

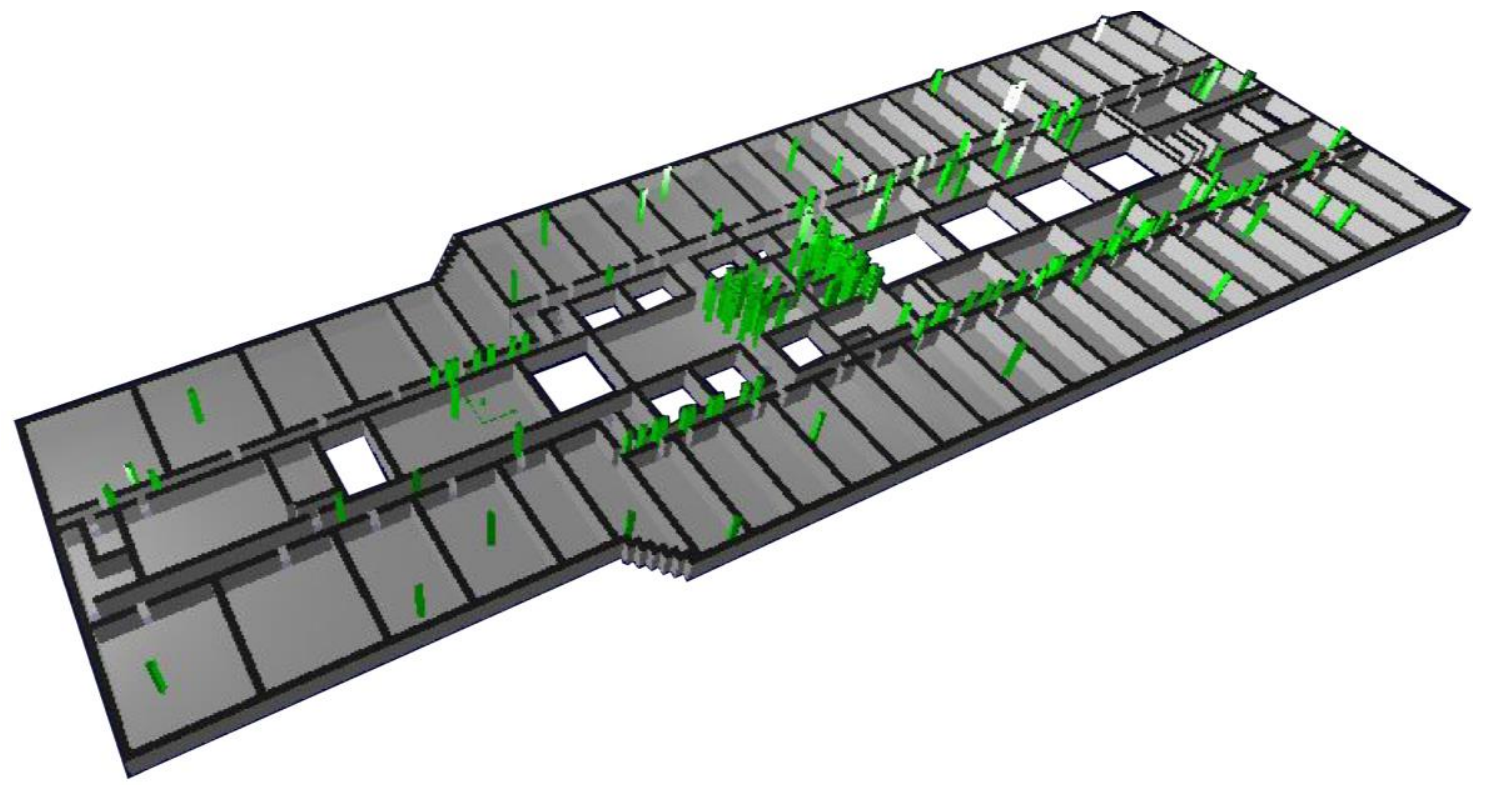

Fig. 9 From AENEAS, screenshot of a simulation step (reference to Deck 6, Case 1) 
Nasso Carlo, Bertagna Serena,

Mauro Francesco, Marinò Alberto, Bucci Vittorio
Simplified and advanced approaches for evacuation analysis of passenger ships in the early stage of design

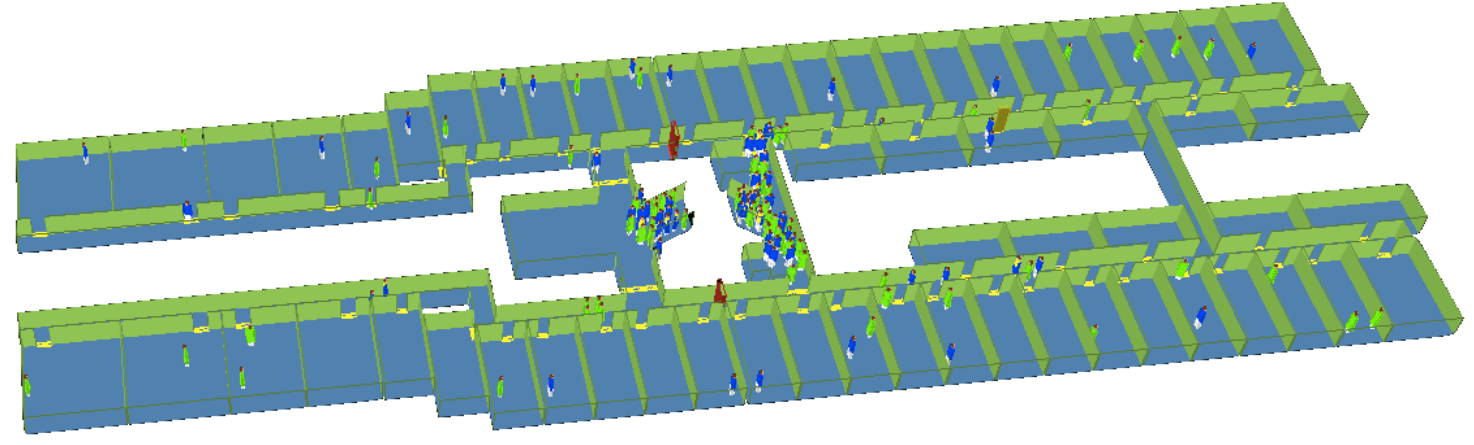

Fig. 10 From EVI, screenshot of a simulation step (reference to Deck 6, Case 1)

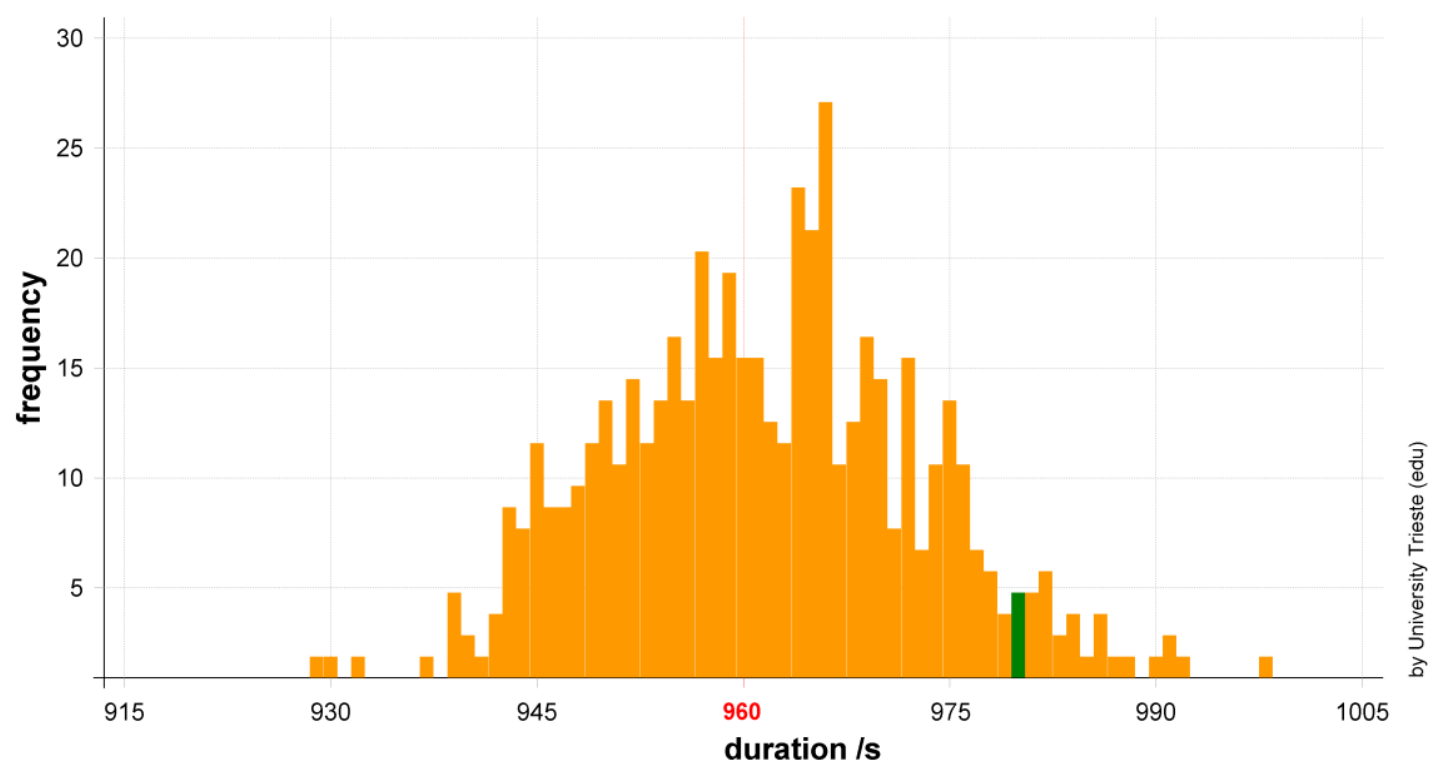

Fig. 11 From AENEAS, frequency of the evacuation duration in Case 1 (green bar is at the 95-percentile)

Table 6 From EVI, evacuation duration vs. evacuability index (Case 1)

\begin{tabular}{|c|c|c|c|c|c|}
\hline$t[\mathrm{~s}]$ & $\begin{array}{c}\text { Evacuability } \\
\text { index }\end{array}$ & $t[\mathrm{~s}]$ & $\begin{array}{c}\text { Evacuability } \\
\text { index }\end{array}$ & $t[\mathrm{~s}]$ & $\begin{array}{c}\text { Evacuability } \\
\text { index }\end{array}$ \\
\hline 980.5 & 0.01 & 1005.0 & 0.35 & 1023.0 & 0.69 \\
\hline 986.0 & 0.03 & 1005.5 & 0.37 & 1023.0 & 0.71 \\
\hline 990.5 & 0.05 & 1006.5 & 0.39 & 1024.5 & 0.73 \\
\hline 990.5 & 0.07 & 1007.0 & 0.41 & 1025.5 & 0.75 \\
\hline 991.5 & 0.09 & 1009.0 & 0.43 & 1028.0 & 0.77 \\
\hline 994.5 & 0.11 & 1011.5 & 0.45 & 1028.0 & 0.79 \\
\hline 995.5 & 0.13 & 1012.0 & 0.47 & 1028.5 & 0.81 \\
\hline 997.0 & 0.15 & 1012.0 & 0.49 & 1030.5 & 0.83 \\
\hline 997.0 & 0.17 & 1012.5 & 0.51 & 1031.0 & 0.85 \\
\hline 997.5 & 0.19 & 1016.0 & 0.53 & 1032.0 & 0.87 \\
\hline 999.0 & 0.21 & 1016.5 & 0.55 & 1033.0 & 0.89 \\
\hline 1000.0 & 0.23 & 1017.0 & 0.57 & 1033.0 & 0.91 \\
\hline 1001.5 & 0.25 & 1017.5 & 0.59 & 1033.0 & 0.93 \\
\hline 1002.0 & 0.27 & 1019.0 & 0.61 & 1033.5 & 0.95 \\
\hline 1002.5 & 0.29 & 1019.5 & 0.63 & 1042.0 & 0.97 \\
\hline 1004.0 & 0.31 & 1020.0 & 0.65 & 1053.5 & 0.99 \\
\hline 1004.0 & 0.33 & 1021.5 & 0.67 & & \\
\hline
\end{tabular}




\subsection{Comparison between the methods and software}

In both software, the Case 4 is the worst one (Table 8 and 9), but the performance standard ( 80 minutes) is fulfilled. Through the 3D representation, it is easy to verify the presence of possible congestion points (for instance, in the case study considered a congestion point at Deck 6 has been noted), while the same analysis is quite difficult within the simplified method. Indeed, the simplified method has not identified any possible congestion point within the two considered cases.

In order to make a complete comparison between the simplified and the advanced methods, the calculation times required by both methods have been analysed. With regard to the simplified method, the low complexity of the various operations involved, makes the calculation time negligible. However, it is necessary to consider not only the pure calculation time, but also the time required to update the population distribution for every scenario. As regards the advanced method, the calculation time required is higher, but the result consists of a batch running of 50 different simulations. Here, the calculation time is strongly influenced by the complexity and dimension of the pedestrian path. For the vessel considered in this study, the total calculation time per each scenario is of about 15 minutes on a regular $2.7 \mathrm{GHz}$ 4 cores workstation. The two software have almost the same calculation time and performances. For more complex and bigger ships, calculation time may increase up to 2 hours per case.

In conclusion, for a geometry like the one considered in this study, the total time needed for the problem modelling and scenarios calculation is fully comparable between simplified and advanced methods.

Table 7 Evacuation duration simplified method

\begin{tabular}{|c|c|c|}
\hline Case & $T[\mathrm{~s}]$ & $t_{T O T}[\mathrm{~s}]$ \\
\hline 1 & 402 & 2452 \\
\hline 2 & 1328 & 3235 \\
\hline 3 & \multicolumn{2}{|c|}{ not considered } \\
\hline 4 & \multicolumn{2}{|c|}{ not considered } \\
\hline
\end{tabular}

Table 8 Evacuation duration advanced method in AENEAS

\begin{tabular}{|c|c|c|c|}
\hline Case & $t_{I}[\mathrm{~s}]$ & \multirow{2}{*}{$T[\mathrm{~s}]$} & $t_{\text {TOT }}[\mathrm{s}]$ \\
\hline 1 & 980 & & \\
\cline { 1 - 2 } 2 & 667 & \multirow{3}{*}{2344} & \multirow{2}{*}{4505} \\
\cline { 1 - 2 } 3 & 1483 & & \\
\cline { 1 - 2 } 4 & 2344 & & \\
\hline
\end{tabular}

Table 9 Evacuation duration advanced method in EVI

\begin{tabular}{|c|c|c|c|}
\hline Case & $t_{I}[\mathrm{~s}]$ & \multirow{2}{*}{$T[\mathrm{~s}]$} & $t_{\text {TOT }}[\mathrm{s}]$ \\
\hline 1 & 1033.5 & & \\
\cline { 1 - 2 } 2 & 643 & \multirow{2}{*}{2510} & \multirow{2}{*}{4713} \\
\cline { 1 - 2 } 3 & 1354.5 & & \\
\cline { 1 - 2 } 4 & 2510 & & \\
\hline
\end{tabular}

\section{Conclusions}

The new IMO Regulation MSC.1/Circ.1533 issued on May 2016 about evacuation analysis of passenger ships has been thoroughly presented, and a case study regarding a 3600person cruise ship has been reported. Both simplified and advanced methods have been considered. In particular, the advanced method has been carried out by two multi-agent software based on virtual reality, both certified by the IMO: AENEAS by DNV-GL and TraffGo, and EVI by the University of Strathclyde-Glasgow. It is worth noting that in the

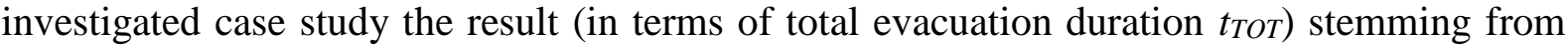
simplified analysis is much smaller than that evaluated by the advanced method. For instance, with reference to the Case Study reported in the paper, by the simplified method the total evacuation duration tтот $_{\text {is }}$ equal to $3235 \mathrm{~s}$, whereas the advanced method carried out with AENEAS gives $t_{T O T}=4505 \mathrm{~s}$, and carried out with EVI gives $t_{T O T}=4713 \mathrm{~s}$. Although both simplified and advanced methods meet the performance standard set by the Circular, a deeper investigation should be done in order to make the results of the simplified method more reliable. 


\section{REFERENCES}

[1] ...: "Interim guidelines for a simplified evacuation analysis on ro-ro passenger ship", MSC/Circ. 909, International Maritime Organization, 1999.

[2] ...: "Guidelines for a simplified evacuation analysis for new and existing passenger ships", MSC/Circ. 1033, International Maritime Organization, 2003.

[3] ...: "Guidelines for evacuation analysis for new and existing passenger ships", MSC/Circ. 1238, International Maritime Organization, 2007.

[4] VASSALOS, D., GUARIN, L., VASSALOS, G.C., BOLE, M., KIM, H.S., MAJUMDER, J.: "Advanced evacuation analysis - Testing the ground on ship", Second International Conference in pedestrian and evacuation dynamics, London, 2003.

[5] LOPEZ PINEIRO, A., PEREZ ARRIBAS, F., DONOSO, R., TORRES, R.: "Simulation of passenger movement on ship emergencies. Tools for IMO regulations fulfilment", Journal of Maritime Research, Vol. II (2005), 1, p. 105-125.

[6] WANG, W.L., LIU, S.B., LO, S.M., GAO, L.J.: "Passenger ship evacuation simulation and validation by experimental data sets", Procedia Engineering $71 \quad$ (2014), p. 427-432. https://doi.org/10.1016/j.proeng.2014.04.061

[7] BUCCI, V., MARINO', A., TRINCAS, G., ZANUTTO, G.: "Innovative tools for advanced evacuation analysis of passenger ships", 18th International Conference on Ships and Shipping Research (NAV), Lecco, 2015.

[8] AZZI, C., PENNYCOTT, A., MERMIRIS, G., VASSALOS, D.: "Evacuation Simulation of Shipboard Scenarios", Proceedings of Fire and Evacuation Modelling Technical Conference, Baltimore, 2011.

[9] GAlEA, E., GRANDISON, A., FILIPPIDIS, L., GWYNNE, S., EWER, J., LAWRENCE, P.: “The Simulation of Fire and Evacuation at Sea.", Proceedings of the 10th International Intaflam conference, Edinburgh, 2004.

[10] PRADILLON, J.Y.: "ODIGO - Modelling and Simulating Crowd Movement on board Ships", 3rd Int. Conference on computer and IT applications in the Maritime Industries (COMPIT), Sigueira, 2004.

[11] GINNIS, A.I., KOSTAS, K.V., POLITIS, C.G., KAKLIS, P.D.: "VELOS: a VR platform for shipevacuation analysis", Computer-Aided Design $42 \quad$ (2010), p. 1045-1058. https://doi.org/10.1016/j.cad.2009.09.001

[12] KLÜPFEL, H.: "Ship Evacuation - Guidelines, Simulation, Validation and Acceptance Criteria", Proceedings of the 4th Int. Conference on Pedestrian and Evacuation Dynamics, Berlin, 2010. https://doi.org/10.1007/978-3-642-04504-2_21

[13] BUCCI, V., MARINO', A., MAURO, F., NABERGOJ, R., NASSO, C.: “On Advanced Ship Evacuation Analysis", 22nd International Conference on Engineering Mechanics (IM 2016), Svratka, 2016.

[14] GALEA, E.R., DEERE, S., BROWN, R., FILIPPIDIS, L. : “An experimental validation of an evacuation model using data sets generated from two large passenger ships", SNAME 2013 Annual Meeting and Expo and Ship Production Symposium: Where Industry and Technology Meet, Bellevue, United States 2013 https://doi.org/10.5957/JOSR.57.3.120037

[15] ZHANG, D, SHAO, N., TANG, Y. : “An evacuation model considering human behavior", 14th IEEE International Conference on Networking, Sensing and Control, ICNSC 2017

[16] GALEA, E.R., BROWN, R.C., FILIPPIDIS, L., DEERE, S.: “Collection of evacuation data for large passenger vessels at sea”, PED 2010, Maryland, 2010. https://doi.org/10.1007/978-1-4419-9725-8_15

[17] BROWN, R., GALEA, E.R., DEERE, S., FILIPPIDIS, L.: "IMO Inf paper summary - Response time data for large passenger ferries and cruise ship", Safeguard Passenger Evacuation Seminar, London, 2012.

[18] ...: "Revised guidelines on the evacuation analysis for new and existing passenger ships", MSC.1/Circ.1533, International Maritime Organization, 2016.

[19] BUCCI, V., MARINO', A., MAURO, F., NASSO, C.: "Evacuation analysis for passenger ship: a new mandatory step for the early-stage design", XXII Symposium Sorta 2016.

[20] SUN, J., GUO, Y., LI, C., LO, S., LU, S.:” An experimental study on individual walking speed during ship evacuation with the combined effect of heeling and trim" Ocean Engineering 2017. https://doi.org/10.1016/j.oceaneng.2017.10.008

[21] KWEE-MEIER, S.T., MERTENS, A., SCHILICK, C.M.: "Evacuations of passenger ships in inclined positions - Influence of uphill walking and external stressors on decision-making for digital escape route 
signage", International Conference on Human Factors in Transportation, AHFE 2016. https://doi.org/10.1007/978-3-319-41682-3_33

[22] ZHANG, D., ZHAO, M., YING, T., YING, T., GONG, Y.T.: "Passenger ship evacuation model and simulation under the effects of storms", Systems Engineering Society of China 2016.

[23] BALAKHONTCEVA, M. KARBOVSKII, V. SUTULO, S. BOUKHANOVSKY, A. "Multi-agent simulation of passenger evacuation from a damaged ship under storm conditions", International Conference on Computational Science, ICCS 2016 https://doi.org/10.1016/j.procs.2016.05.547

Submitted: $\quad$ 13.03.2018. Nasso Carlo, cnasso@units.it Bertagna Serena, sbertagna@units.it

Accepted: $\quad$ 05.06.2019. $\quad$ Mauro Francesco, fmauro@units.it

Marinò Alberto, marino@units.it

Bucci Vittorio, vbucci@units.it

Department of Engineering and Architecture,

University of Trieste, via A. Valerio, 10, I-34127 Trieste 